The complications just described, in our view, detract greatly from the practical utility of these systems as dosimeters, though they do respond to a measurable extent to doses of gamma-radiation as low as 100 rads.

We thank Prof. J. Weiss and Dr. G. R. A. Johnson for the use of a cobalt source and Dr. N. Miller for helpful discussions. One of us (H.J.M.F.) is indebted to the Durham County Education Committee for a grant and the other (J.W.) to the Durham Colleges of the University of Durham for a research fellowship during the tenure of which this work was carried out.

$$
\begin{aligned}
& \text { J. Wilkinson* } \\
& \text { H. J. M. Fitches }
\end{aligned}
$$

Londonderry Laboratory for Radiochemistry, University of Durham, Durham.

Feb. 7.

* Present address : Royal Technical College, Salford.

${ }^{1}$ Miller N., and Wilkinson, J., Farad. Soc. Discuss., 12, 50 (1952).

"Miller, N., "Introduction à la Dosimétrie des Radiations", Actions Chimiques et Biologiques des Radiations (2me série) (Masson et Cie, Paris, 1956).

- Clark, G. L., and Bierstedt, P. E., Radiation Research, 2, 199 (1955).

- Clark, G. I, and Bierstedt, P. E., Radiation Research, 2, 295 (1955).

5 Schnlte J. W. Suttle, J. F., and Wilhelm, R., J. Amer. Chem. Soc., $75,2222(1953)$.

- Klein, A. K., J. Assoc. Offic. Agric. Chemists, 32, 349 (1949).

7 Prevost-Bernas, A., Chapiro, A., Cousin, C., Landler, Y., and Magat, M., Farad. Soc. Discuss., 12,98 (1952).

\section{Effects of Irradiation upon Diodes of the Silicon Junction Type}

A RECENT report by E. H. Cooke-Yarborough et al. ${ }^{1}$, of the Atomic Energy Research Establishment, Harwell, indicated that the minority carrier storage effects in transistors of the point-contact type were reduced by neutron bombardments. This led me to investigate the effects of irradiation upon diodes of the silicon junction type, with the object of reduction of minority camier storage in these. The diodes used in the experiment were the small power type of $50 \mathrm{~mW}$. dissipation which are at present commercially available.

With the kind co-operation of the authorities of the Atomic Energy Research Establishment, a number of these diodes were irradiated over a range from $0.75 \times 10^{14}$ neutrons $/ \mathrm{sq}$. $\mathrm{cm}$. to $8 \times 10^{14}$ neutrons/sq. cm. It was estimated that slow and fast neutrons were present in approximately equal quantities.

After irradiation, the diodes did not exhibit any significant change in the reverse characteristic. A progressive change in the forward conducting characteristic was noted, however, accompanied by a distinct reduction of minority carrier storage. The change noted in the forward conducting characteristic was that increased irradiation caused the abrupt change in forward resistance occurring in these diodes at approximately $0.6 \mathrm{~V}$. to become less abrupt, and the slope resistance to increase. This effect was most marked in cases where irradiation dosage was in excess of $1 \times 10^{14}$ neutrons/sq. cm.

Minority carrier storage, as previously stated, progressively decreased with increased irradiation. Measurement of the carrier storage effect was achieved by passing a forward current of $7 \mathrm{~m}$.amp. for a pericd of 4 usec., and then switching a reverse voltage of $15 \mathrm{~V}$. across the diode. The integrated area of the overshoot, having an exponential decay, is a measure of the carrier storage.

The test was purely for comparative purposes and an accurate measurement of absolute values of stored charge was not attempted; as an approximation, the stored charge for the non-irradiated diodes used was between $1 \times 10^{-9}$ and $3 \times 10^{-9}$ coulomb. Irradiation of $1 \times 10^{14}$ neutrons/sq. $\mathrm{cm}$. reduced this value to less than one-third. Irradiation by $2 \times 10^{14}$ neutrons/sq. cm. caused a further significant reduction, the carrier storage now being less than could be measured with the apparatus used. An estimate, however, places the carrier storage at least an order of magnitude less than that of a nonirradiated diode.

Further work is in progress to establish optimum dosage, which would appear to be between $1 \times 10^{14}$ and $2 \times 10^{14}$ neutrons/sq. $\mathrm{cm}$.

E.M.I. Engineering Development, Ltd.,

R. GorToN

E.M.I. Engineering Develo
Victoria Road, Feltham, Middlesex. Feb. 4.

${ }^{1}$ Cooke-Yarborough, E. H., Florida, C. D., and Stephen, J. H., Proc. Inst. Elect. Eng., 101, Part III, No. 73 (1954). Florida, C.

\section{Reversibility of Fluorescence by Annealing}

ConTINUING the investigations on which I reported in Nature of February 9 , p. 319, I have found that the effect I called fluorescence, reversible by anneal. ing, really embraces two different processes.

In the chemicals mentioned, as well as in some zeolites and in anhydrite from Bleiberg, tested in powdered form, the explanation given in the previous communication is valid : the fluorescence, destroyed by strong heating, is regenerated on renewed lesser heating when water vapour has been adsorbed on the substance. Recently, this effect has been found to be especially marked also in colemanite from Turkey.

In the feldspars, however, and in wollastonite, the effect only occurs if the samples have been touched by hand after the preliminary strong heating. Here the effect is due to particles of skin transferred to the mineral surface. That appreciable quantities of skin substance are transferred to minerals by rubbing has been proved convincingly by Halla and van Tassel ${ }^{1}$ in a note on the smell of sparks struck from rocks. I have now found that pieces of skin taken from the human body show actually a stronger fluorescence after suitable heat treatment.

\section{Institut für Radiumforschung,}

K. Przibram

Vienna. March 16.

${ }^{1}$ Halla, F., and van Tassel, R., Naturwiss., 43, 444 (1956).

\section{Use of Glossy Paper for determining Droplet Sizes}

IN what is often called the 'impressions' technique, droplet sizes are determined by measurements of the traces made by them when they strike a target. Various types of collecting surface are used: glass plates coated with a newly prepared layer of magnesium oxide ${ }^{1}$, glass plates coated with a silicone ${ }^{2}$, absorbent filter paper ${ }^{3}$, or a glossy type of paper. Up to the present, glossy paper has been used only in the United States. Believing that an extra tool 